\title{
FRAY MANUEL DE GUERRA Y RIBERA Y LA DEFENSA DE JUAN JOSÉ DE AUSTRIA: LOS PRIMEROS SERMONES
}

\author{
FRAY MANUEL DE GUERRA Y RIBERA AND THE DEFENSE OF \\ JUAN JOSÉ DE AUSTRIA: THE FIRST SERMONS
}

Francisco Jose GARCIA PEREZ

Universitat de les Illes Balears-IEHM

\section{RESUMEN}

Si hablamos de Juan José de Austria, inevitablemente debemos relacionarlo con el predicador real que mayores elogios le tuvo siempre reservados. El trinitario Fray Manuel de Guerra y Ribera llegó a convertirse en una de las grandes voces del reinado de Carlos II. Y en gran parte, fue gracias a sus vínculos con el príncipe bastardo. Precisamente, este artículo pretende incidir en las íntimas conexiones que existían entre la oratoria sagrada y la política a partir de la alianza que sellaron ambos personajes con el objetivo último de encumbrar a Juan de Austria hacia un lugar privilegiado como sombra del rey.

Palabras clave: Juan José de Austria, Real Capilla, predicador, Sermones. 


\section{ABSTRACT}

If we speak of Juan José of Austria, we must inevitably relate him to the royal preacher who always had the highest praise in store for him. The Trinitarian Fray Manuel de Guerra y Ribera became one of the great voices of the reign of Carlos II. And in large part, it was because of his ties to the bastard prince. Precisely, this article intends to emphasize the intimate connections that existed between sacred oratory and politics based on the alliance that both characters sealed with the goal of elevating John of Austria to a privileged place as the king's shadow.

Keywords: Juan José de Austria, Royal Chapel, preacher, sermons.

\section{INTRODUCCIÓN: LOS PRIMEROS RESPLANDORES DE GUERRA Y RI- BERA}

Una vez se hizo con el poder tras lo que fue un verdadero pronunciamiento militar, Juan José de Austria tuvo muy en cuenta la opinión que emanaba de los púlpitos de Madrid. A fin de cuentas, muchas de aquellas voces habían sido las responsables de construir una verdadera imagen idealizada de sí mismo. Y, entre todos los predicadores que defendieron al príncipe bastardo, fray Manuel de Guerra y Ribera fue, con seguridad, el más apasionado ${ }^{1}$. Sin embargo, la actividad de este predicador real durante los años inmediatamente anteriores al triunfo político de don Juan a menudo ha eclipsado los inicios de esta alianza y también amistad. En este artículo, se pretende revisar los primeros sermones que Guerra y Ribera predicó al príncipe Juan José, y que colocaron ya al trinitario en una posición delicada. De hecho, estos sermones ofrecen datos ciertamente significativos que explican a la perfección las motivaciones del predicador. Además, son un preludio de la situación de guerra abierta entre predicadores que se iba a vivir en 1676, un año antes del asalto al poder de don Juan.

* Este artículo ha podido llevarse a cabo gracias al apoyo de una beca posdoctoral Vicenç Mut Estabilitat concedida por el Govern de les Illes Balears a través del Pla de Ciència, Tecnologia i Innovació de les Illes Balears 2018-2022 y la financiación del proyecto de investigación Novatores en el púlpito. La oratoria sagrada castellana ante la crisis dinástica y el cambio de paradigma cultural (1665-1700) (número de referencia PID2020-117974GB-I00) concedido por el Ministerio de Ciencia e Innovación.

Las abreviaturas utilizadas en este artículo son las siguientes: AAV (Archivio Apostolico Vaticano); AGP (Archivo General de Palacio); AUSA (Archivo Histórico de la Universidad de Salamanca); BNE (Biblioteca Nacional de España).

1 Luciano García Lorenzo, Ideología y moralismo: El padre Manuel de Guerra y Ribera y su aprobación a las comedias de Calderón de la Barca (Burgos: Universidad de Burgos, 1995), 64. 
La figura del predicador real había ido adquiriendo cada vez mayor importancia en la Corte de los Austrias ${ }^{2}$. Aunque las funciones inherentes a estos oradores áulicos estaban en mayor parte destinadas a la instrucción religiosa y moral de las élites, con frecuencia terminaban asumiendo otros roles directamente relacionados con la alta política ${ }^{3}$. Su capacidad para predicar directamente ante sus majestades-enviando unos mensajes que, por otro lado, no podían ser interrumpidos- los convertía en elementos potencialmente útiles. Las distintas facciones cortesanas, miembros de la familia real o el mismísimo monarca empezaron a ser conscientes de la fuerza que emergía de aquella oratoria ${ }^{4}$. Inevitablemente, durante el Seiscientos se constataron casos de predicadores reales que forjaron lazos de amistad y colaboración política con miembros del aparato político de la Monarquía ${ }^{5}$. Esto quizás explique más claramente el hecho de que, cuando se inició la regencia de Mariana de Austria en 1665, el número de predicadores era ya elevadísimo, en parte como reflejo de las necesidades de la Corona de recompensar lealtades y comprar voces capaces de construir un discurso panegírico hacia el trono ${ }^{6}$. En estas circunstancias, con tantos predicadores pugnando por ganarse el favor de la regente, se forjó a fuego lento una alianza que pondría de manifiesto el significativo papel que la oratoria sagrada continuaba jugando en el rumbo de la política. Se trata de la amistad entre el predicador fray Manuel de Guerra y Ribera y el hijo bastardo de Felipe IV, el príncipe Juan José de Austria.

Sobre el padre Guerra contamos con algunos datos biográficos gracias al estudio clásico que en su momento realizó Andrés Soria Ortega. Nacido en la villa de Madrid en 1638, tomó el hábito en la orden trinitaria siendo muy joven? ${ }^{7}$. Hijo de la provincia de Toledo, cursó sus estudios superiores en la Universidad

2 Sobre la importancia que los predicadores reales tenían para las altas esferas del poder véase Fernando Negredo del Cerro, "La palabra de Dios al servicio del Rey. La legitimación de la Casa de Austria en los sermones del siglo XVII", Criticón 84-85 (2002): 295-311.

3 Sobre las funciones del predicador, véase Luciana Gentili, "Cómo el predicador ha de reprender en el púlpito los pecados públicos de los Reyes”, Impossibilia 3 (2012): 56.

4 Antonio Álvarez-Ossorio Alvariño, "Facciones cortesanas y arte del buen gobierno en los sermones predicados en la Capilla Real en tiempos de Carlos II", Criticón 90 (2004): 106.

5 Fernando Negredo del Cerro, "La Capilla Real como escenario de la lucha política. Elogios y ataques al valido en tiempos de Felipe IV”, en La Capilla Real de los Austrias. Música y ritual de corte en la Europa moderna, ed. Juan José Carreras y Bernardo J. García García (Madrid: Fundación Carlos de Amberes, 2001), 324.

6 Francisco José García Pérez, Juan Rodríguez Coronel: un predicador jesuita en la Corte de Carlos II (Madrid-Porto: Sindéresis, 2019), 57.

7 Félix Herrero Salgado, La oratoria sagrada en los siglos XVI y XVII. La predicación en la Compañía de Jesús. Tomo III (Madrid: Fundación Española Universitaria, 2001), 158. 
de Alcalá. En 1662, con veintitrés años cumplidos, fue lector de Teología en el Colegio de la Trinidad de dicha ciudad y, poco después, se trasladó a la Universidad de Salamanca, donde remató su formación académica ${ }^{8}$. Sus años en la ciudad salmantina iban a ser fundamentales en su carrera, porque fue allí donde Guerra y Ribera conoció de primera mano un ambiente de facciones a pequeña escala, que le prepararía para el futuro escenario de la Corte de Madrid. En 1666 fue Maestro de Teología y pasó a residir en el convento que los trinitarios calzados tenían en la ciudad ${ }^{9}$. Durante aquellos años, combinó su preparación para las oposiciones con la actividad en el púlpito. Desde siempre, tuvo un estilo único y muy personal a la hora de predicar sermones. Con una oratoria en ocasiones recargada hasta el aturdimiento, a la vez que repleta de musicalidad y belleza, fray Manuel adquirió confianza y se esmeró como pocos, hasta el punto de que, tan solo dos años después de empezar a dar clases en Salamanca, consiguió uno de los mayores premios a los que podía aspirar cualquier orador: el título de predicador del rey ${ }^{10}$.

Cuando Guerra y Ribera llegó a la Corte, esta se hallaba condicionada por el gobierno de regencia instaurado tras la muerte de Felipe IV. Desde 1665, Mariana de Austria era regente y mantenía a su hijo, el rey-niño Carlos II, aislado de otras influencias que no fuesen la suya. Era lógico, por tanto, que los nuevos aspirantes a predicador se esmerasen por impresionar a la que, en última instancia, había autorizado su entrada en la Real Capilla ${ }^{11}$. Sin embargo, y contra todo pronóstico, Guerra y Ribera rompió la línea trazada y se fijó en otro miembro de la familia real: Juan José de Austria, hijo bastardo de Felipe IV y, por lo tanto, también hermanastro del rey. Desde que era joven, don Juan había mostrado una ambición jamás disimulada, siempre encaminada a asumir un rango en apariencia igual al de un infante. El nuncio papal había escrito a Roma que, "se bene non fu dichiarato da Filippo IIII per suo figlio naturale, è stato sempre tenuto per tale"12. Sus campañas en numerosos frentes de la Monarquía de su padre, su reconocimiento definitivo como hijo natural y la construcción de una casa propia, eran signos claros del papel que Juan José de Austria iba a desempeñar en la alta política ${ }^{13}$. Sin embargo, su madrastra no tenía intención de mantenerlo

8 Andrés Soria Ortega,El Maestro Fray Manuel de Guerra y Ribera y la oratoria sagrada de su tiempo(Granada: Universidad de Granada, 1950), 39.

9 AUSA, Matrículas, lib. 374, f. 12.

10 AGP, Personal, Caja 7730, ex. 9. Expediente de fray Manuel de Guerra y Ribera.

11 Francisco José García Pérez, "La reforma de predicadores en la Real Capilla de Carlos II", Hispania Sacra 71 (2019): 564.

12 AAV, Segreteria di Stato, Spagna, 139, f. 624.

13 Véase Koldo Trápaga Monchet, La actividad politica de don Juan [José] de Austria en el reinado de Felipe IV (1642-1665) (Madrid, Polifemo, 2019). 
cerca. Fue, precisamente, en este ambiente en que hizo su aparición el predicador trinitario. Aunque no se tiene constancia de cuál fue el papel que tomó el padre Guerra en estos primeros momentos, todo indica que quedó desde el principio fascinado por la figura del príncipe don Juan ${ }^{14}$. De hecho, como se viene anunciando, el predicador dedicaría su voz y toda su energía a convertirse en el panegirista por excelencia del príncipe bastardo. Lo curioso, sin embargo, es que Guerra y Ribera consiguió llamar la atención de don Juan muy lejos del púlpito de la real Capilla.

\section{REHABILITANDO LA IMAGEN DEL PRÍNCIPE: LOS SERMONES PRE- DICADOS EN 1670 Y 1671}

Las intrigas políticas de don Juan habían provocado su forzada partida al reino de Aragón, donde terminó siendo nombrado vicario general ${ }^{15}$. Sus continuados empeños por defenestrar al que, por aquel entonces, era el consejero más valioso de doña Mariana, su confesor austríaco, se habían traducido en una victoria pírrica. Juan Everardo Nithard fue enviado a Roma y el gobierno de regencia se mantuvo estable, sostenido por los firmes pilares que le otorgaba el testamento de Felipe IV. Además, el príncipe se había visto obligado a retirarse de Madrid y mantenerse expectante en Zaragoza, siempre atento a una nueva oportunidad. Curiosamente, tan solo un año después de la marcha del príncipe, fray Manuel de Guerra y Ribera solicitó los debidos permisos al rey para trasladarse a Zaragoza. De hecho, predicó durante dos años consecutivos ante don Juan, lo cual puede indicar que el primer encuentro fue todo un éxito y seguramente forjó lazos entre aquellas dos figuras. Lo importante es que aquellos sermones iban a tener una importancia significativa, no ya en la ciudad donde residía el príncipe, sino en la misma Corte de Madrid.

Sobre la primera estancia de Guerra y Ribera en Zaragoza, no tenemos demasiados datos, al margen del propio sermón, puesto que todavía no había empezado a regentar la cátedra de Artes, que le obligaba a solicitar autorización al claustro para ausentarse de sus obligaciones académicas. Poco imaginaba nadie que aquella visita a la ciudad zaragozana iba a convertirse en un punto de

14 Soria Ortega, Fray Manuel de Guerra y Ribera, 62.

15 Antonio Álvarez-Ossorio Alvariño, "Fueros, cortes y clientelas: el mito de Sobrarbe, Juan José de Austria y el reino paccionado de Aragón (1669-1678)", Pedralbes: Revista d'Història Moderna 12 (1992): 244. 
inflexión en la carrera de Guerra y Ribera en la Corte de los Austrias ${ }^{16}$. Por aquellas fechas, el trinitario desplegó ya los primeros ecos de su arte oratoria. De hecho, predicó en diversas iglesias zaragozanas durante la Cuaresma de 1670 $\mathrm{y}$, como no podía ser de otro modo, terminó siendo requerido para predicar ante el personaje más eminente de la ciudad: el príncipe don Juan ${ }^{17}$. Aquel fue el primer encuentro, por lo menos del que tengamos constancia, entre el trinitario y Juan José de Austria. Este segundo residía en el Palacio Arzobispal, consumido por su ambición frustrada y conspirando en la sombra para retornar a Madrid y jugar su propio papel en la alta política. Lo claro es que invitó a Guerra y Ribera a que le predicara varios sermones en su capilla privada.

Aquellos sermones se convirtieron, de principio a fin, en un elogio continuo al príncipe ${ }^{18}$. De hecho, incluyeron referencias a personajes y pasajes bíblicos que volverían a ser utilizados en sermones futuros, y que se iban a convertir en un recurso muy útil para Guerra y Ribera en su obsesiva defensa de Juan José de Austria y su derecho a asumir un papel preponderante en la alta política, o lo que es lo mismo, en convertirse en el director político del propio rey. Debe suponerse que, si estos sermones provocaron ya un primer escándalo una vez fueron impresos, quiere decir que el mensaje que el trinitario incluía en ellos era perfectamente entendible, precisamente porque los predicadores reales de la época repetían el uso de personajes bíblicos en función de sus propios intereses. Tendremos ocasión de comprobarlo. Lo importante, a fin de cuentas, es que los sermones predicados ante el príncipe don Juan suponen, en muchos sentidos, la primera mecha del grupo de los que iban a ser conocidos más adelante como los "malcontentos", todavía en un momento en el que los apoyos que el príncipe tenía en Madrid eran casi marginales. Guerra y Ribera se convirtió, de hecho, en su voz, y supo construir con la fuerza de sus palabras una imagen idealizada e interesada del príncipe.

Tratando sobre la decisión de don Juan de alejarse de la villa coronada, acto que muchos habían criticado abiertamente, Guerra y Ribera le ofrecía ánimos y le recordaba que "no hay lugar por alto, exento de peligros. Por alto parece que

16 Francisco José García Pérez, "La oratoria sagrada como arma política: los predicadores reales de Juan José de Austria", Obradoiro de Historia Moderna 26 (2017): 245.

17 Soria Ortega, El Maestro Fray Manuel, 62.

18 El hecho de que Guerra y Ribera presentase ya un discurso panegírico no significa necesariamente que se hubiese decantado claramente hacia el bando de don Juan. Los predicadores reales, y también por supuesto el trinitario, aprendieron muy pronto a extraer ventajas con sus palabras. $\mathrm{Su}$ capacidad para ser lisonjeros cuando se subían al púlpito podía traducirse en premios evidentes. Lo curioso, sin embargo, es que los brillos del éxito no parecían provenir de Zaragoza, sino de la Corte madrileña, donde Guerra y Ribera acababa de ser nombrado predicador real. García Pérez, "Los predicadores de Juan José", 244. 
está más distante, y vive más vecino; porque en las cumbres afilan sus enojos los rayos. Pero con Dios no hay riesgo, sin Dios la felicidad es peligro" 19 . A continuación, recuperaba la figura de San Pedro y su forzada huida una vez apresaron a Cristo. Lejos de ser visto como un traidor y un cobarde, Guerra y Ribera lo retrataba como alguien prudente. "Lo que resta en la gloria de esta acción, es que, volviendo Pedro a la Corte de Jerusalén, desvanecidas las nubes de prisiones y rotos los enigmas de grillos, no refiere el Texto que alentase la más mínima voz contra tantos" ${ }^{\text {"20 }}$. Obviamente, la figura de San Pedro, vicario de Cristo, ofrecía semejanzas demasiado evidentes con la de don Juan, vicario del rey en Aragón. Ambos se habían visto obligados a huir, pero, al igual que San Pedro, Juan José de Austria tenía reservado su retorno seguro a la Corte. Sin embargo, Guerra y Ribera no se detuvo aquí. De hecho, recuperó otros personajes que ofrecían similitudes mucho más descaradas.

Sacando a colación la historia de David, el predicador trinitario se centraba en la amarga situación que tuvo que sufrir cuando el rey Saúl ordenó su detención. Pese a todo, David no podía culpar al rey de Israel: "Luego no me tengo de enojar con mi Rey, dice David, sino cortarle esta mala tela de que se viste, para que nunca la tenga" ${ }^{21}$. Por aquel entonces, era ya de dominio público el enfrentamiento o desavenencias que don Juan había librado con el confesor de la reina, el austríaco Juan Everardo Nithard. Como se viene diciendo, el príncipe había presionado militarmente a la propia regente, y por extensión a la Junta de Gobierno, para que "sea precisa la salida de estos Reinos del P. Confesor"22. Aunque Mariana de Austria se había visto forzada a transigir y enviar a su confidente a Roma, aquello también supuso un destierro dorado para el hijo bastardo de Felipe IV. Pues bien, lo que parecía decir Guerra y Ribera en su sermón, precisamente era que, al igual que David arriesgó su propia vida con tal de extirpar la maledicencia cortesana que rodeaba al rey Saúl-representada como unos ropajes que el rey vestía y que David se empezó en cortar-,don Juan tenía la obligación de apartar las malas influencias que Nithard ejercía sobre la reina, aunque fuese con medios violentos: "es evidente de la Real Benignidad de este clementísimo Príncipe que, a poder remediarlo, sin cortarle el vestido, lo hubiera practicado. [...] Fue preciso cortar, pero aun esta, que parecía violencia, la

19 Fray Manuel de Guerra y Ribera, Sermones que predicaron al serenissimo Señor, el Señor D. Juan de Austria, en su capilla de Palacio en los años de 1670 y 1671 (Zaragoza: Juan de Ybar, Zaragoza, 1671), 1.

20 Guerra y Ribera, Sermones que predicaron, 2.

21 Guerra y Ribera, Sermones que predicaron, 12.

22 AGP, Registro, libro 10327. Documentos relativos a Mariana de Austria y Don Juan de Austria, fol. 78 . 
meditó su discreción con templanza" ${ }^{23}$. El propio don Juan, en una carta dirigida a doña Mariana meses antes de provocar la caída en desgracia de Nithard, ya hablaba sobre estas supuestas malas influencias alrededor de la corona: "Suplico a V.M. de rodillas, con lágrimas del corazón, que no oiga V.M. ni se deje llevar de los perversos consejos de ese emponzoñado basilisco [Nithard]"24.

A continuación, Guerra y Ribera recuperaba a otro personaje bíblico no exento de controversia: Absalón. Este príncipe había traicionado a su padre, el rey David, después de que su hermana Tamar fuese violada por el hermanastro de ambos, el hijo mayor del rey. Finalmente, la desgracia acabó con la ejecución de Absalón en manos de un allegado de David. Lo importante, de cara a este artículo, son las palabras que profirió Guerra y Ribera, quien, tratando el asesinato de Absalón, hablaba en estos términos: "Aun en el corazón no basta una muerte. Porque este amabilísimo Príncipe había conquistado con sus agrados el corazón del Rey. De los Grandes y Ministros. Y de los Pueblos"25. Lejos de sacar a relucir los supuestos motivos que habían llevado a David a planificar la ejecución de su hijo, como bien hicieron los jesuitas en sus sermones, Guerra y Ribera mostraba una imagen idealizada del príncipe de Israel.

No deja de ser curioso que los predicadores reales utilizaran a este príncipe en función de si se trataba de defender o atacar al propio don Juan. Mientras que Guerra y Ribera se valió de esta figura en los mejores términos posibles, como veremos a continuación, los predicadores de la Compañía de Jesús, enconados enemigos de Juan José, retratarían a Absalón muy negativamente. El propio Nithard, denunciando el acoso al que se veía continuamente expuesto, comparaba a don Juan con aquel príncipe ingrato. Hablando sobre las supuestamente injuriosas y violentas palabras que le dedicaba en sus cartas, el confesor de la reina declaraba que no deseaba venganza, "sino perdón y misericordia al que las pronunció [don Juan], imitando al Santo Rey David que, fugitivo de la persecución de su hijo Absalón, [...] queriendo sus soldados vengarlo, prohibióselo"26. En 1676, coincidiendo con uno de los períodos más convulsos del reinado de Carlos II, y en mitad de una guerra de sermones, el jesuita Juan Rodríguez Coronel, abnegado defensor de doña Mariana en su papel de regente, utilizó también a Absalón $^{27}$. "Los atrevimientos del Infante Absalón le obligaron a su padre David a poner en campaña un ejército contra él y los conjurados que, o por lisonjearle

27 García Pérez, Juan Rodríguez Coronel, 104.

Guerra y Ribera, Sermones que predicaron, 12.

BNE, ms. 18055, f. 279.

Guerra y Ribera, Sermones que predicaron, 27.

AGP, Registro, libro 10327. Documentos relativos a Mariana de Austria y Don Juan de Austria, 
o por mal contentos con la severidad de David, se hicieron con el Infante parciales"28. Frente a la enconada defensa que Guerra y Ribera hacía de Absalón, Rodríguez Coronel lo retrataba, con claras referencias a don Juan, como un príncipe conspirador y desleal a la autoridad regia, quizás como los hijos de la Compañía veían realmente a aquel que había defenestrado políticamente a Nithard y ahora mantenía el cerco siempre constante sobre el gobierno de regencia.

En 1671, Guerra y Ribera volvió a ser invitado a predicar ante su alteza en su capilla privada. Los religiosos del Hospital General de dicha ciudad le "habían elegido para que fuese a predicar a aquella casa la Cuaresma que viene al $\mathrm{M}^{\mathrm{o}}$ Fr. Manuel Guerra y Ribera" ${ }^{29}$. De ese modo, el trinitario solicitó permiso al claustro universitario para volver a Zaragoza un año más. No es difícil imaginar que los sermones del año anterior hubiesen conseguido fascinar al príncipe con tan atrevidos elogios hacia su persona. Pues bien, el predicador continuó con aquellas dinámicas y terminó de sellar su amistad con don Juan. Comenzó hablando sobre la figura de Cristo en su momento más difícil, el calvario. "Le sospecháis delincuente; porque le contempláis infeliz! Luego es ceguedad: pues tenéis por culpado, porque le miráis perseguido; y no todos los perseguidos son culpados" ${ }^{\prime 0}$. Juan José de Austria estaba experimentando, en muchos sentidos, un exilio forzoso, puesto que se le mantenía alejado de la Corte de Madrid, frustrando sus ambiciones políticas. Sin embargo, Guerra y Ribera lo liberaba de toda culpa. Más bien al contrario, el príncipe se hallaba en aquella situación porque había arriesgado todo por el bien de la Monarquía, y también de su hermanastro el rey. "Pero qué importa, infeliz dichoso, dice Cristo, que te acusan esos ministros míos, porque te ignoran. [...] Admirados los ministros que le calumniaban, abren los ojos. No se ha visto semejante acción en la prolija carrera de los siglos" $"$.

A continuación, recuperaba a José de Egipto, otro de los recursos más utilizados por Guerra y Ribera durante los años siguientes cuando se trataba de elogiar el papel político de don Juan y, llegado el momento, justificar su necesario lugar como valido del rey. Gracias a sus sueños proféticos, José se había convertido en una especie de subalterno del propio faraón. "Mirose José virrey de Egipto, forastera provincia de su Patria, si bien por lo confinante, vecina. Tan aclamado en ella, que le intitulaban el Salvador, que los había venido a

28 Juan Rodríguez Coronel, Sermones exhortatorios y de Cuaresma. Tomo II (Madrid: imp. Juan García Infanzón, 1695), 92.

29 AUSA, Actas de Claustros y Juntas de la Universidad 1670-1671,140, f. 11.

30 Guerra y Ribera, Sermones que predicaron, 35.

31 Guerra y Ribera, Sermones que predicaron, 35. 
redimir"32. Y terminaba su sermón siendo todavía más atrevido, en una especie de clímax final. Recuperando una vez más la desesperada situación que vivió David en su huida de Israel, y que después se traduciría en su momento de mayor gloria, Guerra y Ribera parecía comparar a aquel rey bíblico con el propio príncipe don Juan, en un intento desesperado por hacerle ver que las tornas podían cambiar en su favor:

Oh, quiera Vuestra Altísima Providencia corra desatado el Oráculo de este Vaticinio! Si se copian, Señor Divino, las desgracias, retrátense con igualdad las fortunas. Ha de haber para la persecución pinceles, sin que haya para la serenidad colores. No lo espero; que, entre las congojas de la tempestad, enciende sus colores el Iris. Cese, pues, la tempestad, vista el Cielo otro color $^{33}$.

Guerra y Ribera utilizó a José de Egipto como un recurso muy útil cuando se trataba de defender la presencia del príncipe solo dos pasos por detrás del trono. En 1677, una vez que Juan José de Austria se hizo con el poder, exilió a la reina madre a Toledo con el beneplácito de Carlos II e inició una purga política que se tradujo en la expulsión de numerosos opositores del Real Alcázar de Madrid, Guerra y Ribera predicó ante su alteza una vez más. Tratando sobre la figura del perfecto valido, lo que era también una clara referencia al papel que parecía haber asumido su flamante príncipe, decía: "a tres insignes validos celebran las sagradas letras, a José de Faraón, a Daniel de Darío, y a Aman de Asuero; duran los dos y no Aman; porque el valimiento de José y Daniel fue fundado en insignes méritos; el de Aman fue sin haber hecho servicios"34.

Como se viene diciendo, aquellos sermones despertaron la admiración de don Juan. Las bellas palabras que prodigaba el padre Guerra surtieron el efecto deseado. De hecho, iban a tener también su eco en Madrid. Muchos conocieron de primera mano el éxito del trinitario mientras predicaba en Zaragoza. Y fueron precisamente los aliados de don Juan en la Corte los que le sacaron mayor provecho, porque los sermones fueron impresos en Madrid ese mismo año de 1671 y, según parece, despertaron no pocos recelos entre los opositores de Juan José de Austria. Quizás por eso, un año después de predicar en Zaragoza, Guerra y Ribera fue llamado a comparecer ante el tribunal de la Inquisición en Valladolid para que se examinase el contenido de estos. Lo curioso es que el trinitario tenía sus sospechas sobre quien le había denunciado: "La voz es que los PP. Jesuitas son los delatores. [...] Solo un motivo puede enflaquecer mi dolor, y es discurrir

32 Guerra y Ribera, Sermones que predicaron, 47.

33 Guerra y Ribera, Sermones que predicaron, 49.

34 Fray Manuel de Guerra y Ribera, Primera parte de la Quaresma continua (Madrid: imp. Julián de Paredes, 1679), 342. 
si acaso la Compañía ha hecho juicio que estos sermones son contra algún sujeto suyo" 35 . En efecto, el padre Guerra tenía motivos sobrados para sospechar de los hijos de San Ignacio ${ }^{36}$. La caída en desgracia de Nithard no se había traducido en un retroceso de la presencia jesuítica en la Real Capilla. Todo lo contrario, Mariana de Austria se había formado una auténtica cortina de panegiristas que pertenecían a la Compañía. Solamente en 1670, habían entrado de una sola vez tres de los grandes valedores jesuitas que la regente iba a tener en el púlpito regio. El patriarca de Indias había escrito a doña Mariana "deseando que sean todos sujetos muy selectos en la predicación y de toda satisfacción mía; no hallando inconveniente, me ha parecido proponer a V.M. tres sujetos de la Compañía" ${ }^{37}$. Uno de ellos era Juan Rodríguez Coronel, una de las grandes voces jesuíticas del momento, heredero de la oratoria legada por Manuel de Nájera y digno oponente de Guerra y Ribera en el púlpito.

De hecho, aquellos fueron años de una auténtica batalla dialéctica que tuvo divididos a los predicadores de la Real Capilla, y que giró siempre en torno a los dos satélites en la vida del joven rey: Mariana de Austria y el príncipe Juan $J_{o s e ́}{ }^{38}$. Numerosos sermones, cargados unos de bellas alabanzas y otros de feroces críticas, se predicaron en las principales iglesias de Madrid y en la misma Corte. Pero lo más importante, de cara a este artículo, era que fray Manuel de Guerra y Ribera había tomado ya partido. La publicación de los sermones predicados en Zaragoza le señalaba como abierto aliado del príncipe don Juan en el púlpito regio. De hecho, la actitud del trinitario podría considerarse incluso como temeraria, puesto que, hasta la proclamación de la mayoría de edad del rey en 1675, las posibilidades reales de que don Juan desempeñase un rol político en la Corte eran todavía marginales. Sin embargo, Guerra y Ribera se unió a la batalla de sermones que empezó a desplegarse en los años en los que Mariana de Austria volvía a mostrar en la Corte a un nuevo favorito. Y todos sus intentos estuvieron centrados en defender al príncipe Juan José de Austria, aun

35 AUSA, Papeles Varios, 905, f. 32 v.

36 Todo indica que la causa inquisitorial no llegó más allá de una severa reprimenda y amonestación, puesto que el trinitario volvió a transitar la Corte durante ese mismo año, pero ilustra perfectamente el ambiente radicalizado que ya se vivía alrededor de los predicadores reales. García Pérez, Juan Rodríguez Coronel, 96.

37 AGP, Personal, Caja 7734, ex. 7. Expediente de Juan Rodríguez Coronel.

38 Para conocer las disputas entre don Juan y Mariana de Austria sigue siendo imprescindible el estudio biográfico del duque de Maura, que ofrece un detallado registro de cómo fueron evolucionando las relaciones entre la regente y el príncipe durante los primeros años de regencia. Véase Gabriel Maura Gamazo, Carlos II y su corte. Ensayo de reconstrucción biográfica. Volumen I (1661-1669) (Madrid: Boletín Oficial del Estado, 2018). 
a costa de los evidentes riesgos que suponía el hecho de lanzar críticas hacia el palco mismo de los reyes.

\section{CONCLUSIONES:}

Uno de los motivos que mayormente justifican la fama que alcanzó fray Manuel de Guerra y Ribera durante el siglo XVII es, precisamente, su apasionada y, en ocasiones, temeraria defensa de don Juan. No se puede comprender el impulso que alcanzó la imagen de este príncipe bastardo en el Madrid de la regencia sin tener presentes los sermones que el trinitario predicó siempre que tuvo oportunidad. Curiosamente, los orígenes de esta amistad, es decir, el momento en el que ambos personajes sellaron un pacto sin nombre, no han sido todavía estudiados en profundidad. Soria Ortega no prestó a estos primeros sermones la importancia que merecían, puesto que en ellos se hayan las claves para comprender muchas de las referencias que los predicadores reales iban a utilizar siempre que se refiriesen a don Juan. Absalón, José de Egipto o el rey David son solo algunas de las figuras que se relacionaron, de un modo positivo o negativo, con el hijo bastardo de Felipe IV. Y, en muchos sentidos, los sermones predicados en 1670 y 1671 son un preludio de lo que se iba a convertir en algo común en la Real Capilla durante los siguientes.

Aunque los sermones fueron predicados durante la Cuaresma, el uso de temáticas relacionadas con aquel período litúrgico no quedó reducido a la función para la que debía subirse al púlpito un predicador. Como ha podido comprobarse, la oratoria sagrada, y en especial la que se predicaba en la Real Capilla, había sufrido un proceso de instrumentalización política que venía dándose desde inicios del siglo XVII. Los predicadores reales se habían convertido en una élite palatina que también participaba de las dinámicas de facciones que se respiraban en la Corte. Por eso mismo, Guerra y Ribera decidió muy pronto tomar partido $\mathrm{y}$, al igual que hicieron los jesuitas con la reina madre, entregó su voz al príncipe bastardo Juan José de Austria.

Como se viene diciendo, el trinitario aprovechó la oportunidad de predicar ante su alteza para ir un paso más allá de la que era su misión oficial, es decir, declamar sermones conectados con la época cuaresmal, construyendo de ese modo un auténtico discurso panegírico de don Juan. De hecho, ambos sermones mostraban la imagen de un príncipe perfecto, mediante el uso de figuras ensalzadas en el Antiguo Testamento. La huida de David para salvarse de la ira de Saúl parecía un reflejo del exilio al que se había visto forzado don Juan tras su fallido asalto al poder; la figura del príncipe Absalón, lejos de ser retratada como 
la de un príncipe ambicioso y traicionero, mostraba a un príncipe amado por su pueblo e injustamente tratado. Finalmente, José de Egipto ejemplificaba el papel que aún podía desempeñar Juan José de Austria: el gobierno político al lado de su hermanastro, Carlos II. Guerra y Ribera utilizó a José como el prototipo de perfecto valido, desinteresado en su propia riqueza y únicamente decidido a salvar la Monarquía de sus enemigos.

En definitiva, los sermones predicados en 1670 y 1671 nos muestran a un fray Manuel de Guerra y Ribera que todavía estaba aprendiendo a desarrollar sus dotes oratorias, pero que ya anunciaba los tortuosos caminos por los que iba a sumergirse durante el resto de sus años como predicador real. Su conflicto con el tribunal inquisitorial, aunque finalmente se solucionó en su favor, esconde, por un lado, el enorme recelo que Guerra y Ribera empezó a despertar entre numerosos grupos de poder dentro de la Corte, así como la importancia que iba ganando el trinitario en el púlpito de la Real Capilla. De hecho, cuando el grupo de opositores a doña Mariana, denominado comúnmente como los "malcontentos", no existía como tal, el predicador trinitario se había decantado abiertamente por el príncipe bastardo, aun cuando este se hallaba con pocas probabilidades todavía de alcanzar su objetivo de regresar a Madrid y participar en las dinámicas políticas de la Monarquía.

\section{REFERENCIAS BIBLIOGRÁFICAS}

Álvarez-Ossorio Alvariño, Antonio. "Fueros, cortes y clientelas: el mito de Sobrarbe, Juan José de Austria y el reino paccionado de Aragón (1669-1678)". Pedralbes: Revista d'Historia Moderna 12 (1992): 239-292.

Álvarez-Ossorio Alvariño, Antonio. "Facciones cortesanas y arte del buen gobierno en los sermones predicados en la Capilla Real en tiempos de Carlos II". Criticón 90 (2004): 99-123.

García Lorenzo, Luciano. Ideología y moralismo: El padre Manuel de Guerra y Ribera y su aprobación a las comedias de Calderón de la Barca. Burgos: Universidad de Burgos, 1995.

García Pérez, Francisco José. "La oratoria sagrada como arma política: los predicadores reales de Juan José de Austria". Obradoiro de Historia Moderna 26 (2017): 237-265.

García Pérez, Francisco José. Juan Rodríguez Coronel: un predicador jesuita en la Corte de Carlos II. Madrid-Porto: Sindéresis, 2019.

García Pérez, Francisco José. "La reforma de predicadores en la Real Capilla de Carlos II”. Hispania Sacra 71 (2019): 563-575.

Gentili, Luciana. "Cómo el predicador ha de reprender en el púlpito los pecados públicos de los Reyes". Impossibilia 3 (2012): 54-66. 
Guerra y Ribera, Fray Manuel de. Sermones que predicaron al serenissimo Señor, el Señor D. Juan de Austria, en su capilla de Palacio en los años de 1670 y 1671. Juan de Ybar, Zaragoza, 1671.

Guerra y Ribera, Fray Manuel de. Primera parte de la Quaresma continua. Madrid: imp. Julián de Paredes, 1679.

Maura Gamazo, Gabriel. Carlos II y su corte. Ensayo de reconstrucción biográfica. Volumen I (1661-1669). Madrid: Boletín Oficial del Estado, 2018.

Mitchell, Silvia Z. Queen, Mother and Stateswoman. Mariana of Austria and the Government of Spain. Pensylvania: Pensylvania University Press, 2019.

Negredo del Cerro, Fernando. "La Capilla Real como escenario de la lucha política. Elogios y ataques al valido en tiempos de Felipe IV". En La Capilla Real de los Austrias. Música y ritual de corte en la Europa moderna, editado por Juan José Carreras y Bernardo J. García García, 323-344. Madrid: Fundación Carlos de Amberes, 2001.

Negredo del Cerro, Fernando. "La palabra de Dios al servicio del Rey. La legitimación de la Casa de Austria en los sermones del siglo XVII". Criticón 84-85 (2002): 295-311.

Rodríguez Coronel, Juan. Sermones exhortatorios y de Cuaresma. Tomo II. Madrid: imp. Juan García Infanzón, 1695.

Ruiz Rodríguez, Ignacio. Fernando de Valenzuela: orígenes, ascenso y caída de un duende de la corte del rey hechizado. Madrid: Dykinson, 2008.

Soria Ortega, Andrés. El Maestro Fray Manuel de Guerra y Ribera y la oratoria sagrada de su tiempo. Granada: Universidad de Granada, 1950.

Trápaga Monchet, Koldo. La actividad política de don Juan [José] de Austria en el reinado de Felipe IV (1642-1665). Madrid, Polifemo, 2019.

Francisco José García Pérez Instituto de Estudios Hispánicos en la Modernidad (IEHM)

Universitat de les Illes Balears Edificio Ramon Llull, Cra. de Valldemossa, km. 7.5

07122 Palma de Mallorca (España) https://orcid.org/0000-0002-9459-3550 